\title{
The impact of parental self-esteem and parental rearing behavior on adolescent attachment to parents
}

\author{
Anbo Yang $^{1}$ \\ College of Psychology and Cognitive Science, East China Normal University
}

\begin{abstract}
In this study the relationship of parental self-esteem, parental rearing and adolescent adult attachment was investigated. A total 448 senior high school students completed EMBU (Egna Minnen av Barndoms Uppfostran, or "Own memories of parental rearing", Perris et al., 1980), the Experiences in Close Relationships Scale (ECR; Brennan, Clark, \&Shaver, 1998), and their parents completed The Rosenberg Self-Esteem Scale (SES; Rosenberg, 1965). The results suggested that parental global self-esteem has no effect on the adolescent attachment to parents. Parental positive rearing behaviors have been significantly associated with avoidance to parents. Furthermore, the negative rearing behaviors, such as paternal denying and rejecting, maternal punitiveness, maternal overinvolved and overprotective behavior, can predict the adolescent avoidance and anxiety to parents.
\end{abstract}

Keywords: parental self-esteem; parental rearing; adult attachment; late adolescents.

\section{Adult Attachment Theory}

According to Bowlby, children develop an attachment style during the early stages of their life (Bowlby, 1973, 1988). Through interaction with their caregivers, children develop strategies to adjust their affect and behaviors related to attachment (Belsky \& Cassidy, 1994; Main, Kaplan, \& Cassidy, 1985). In their first year of life, infants develop expectations that their parents are available and the world is secure and trustworthy. When the caregiver's response fits their expectations, they acquire a model of self as loved and valued and a model of others as warm and loving. These initial expectations form internal working models, which include the belief that self is lovable and caregiver is available. In other words, children develop a secure attachment style. On the other hand, children develop a model of self as unloved and rejected and a model of others as unloving and rejecting, i.e., they obtain an insecure attachment style (Muris et al., 2004). This internal working model is important not only for individual's basic

\footnotetext{
${ }^{1}$ Correspondence concerning this article should be addressed to Anbo Yang, College of Psychology and Cognitive Science, East China Normal University, Shanghai, 200062, China. E- mail: ABYang@gmail.com
} 
psychological organization (see Sroufe \& Waters, 1977; Parker et al., 1992), but also has an important influence on the quality, style and course of later relationships (Flaherty and Richman, 1986; Sarason et al., 1986; Rodriguez et al., 1993; for a more comprehensive review see Parker et al., 1992).

\section{Parental self- esteem, parental rearing and children behavior}

Self-esteem, an important social psychological concept, has been studied by many researchers. They use the term "self-esteem" or other related terms (e.g., self, selfconcept, self-evaluation, self-respect, self-confidence) in their studies (Rosenberger, et al., 1989). Most of the literature which study self-esteem is concerned about global selfesteem, that is, the individual's positive or negative attitude toward the self as a totality. Kohn and Schooler (1969) showed that the Rosenberg Self-Esteem Scale (Rosenberg 1979) contained two components: self-confidence and self-deprecation. Owens (1993) has reconfirmed the existence of the self-confidence and self-deprecation components of self-esteem with empirical research. He also indicated that both components fit well into a second-order construct of global self-esteem, with self-confidence having an appreciably higher association than self-deprecation with global self-esteem.

Self-esteem was supposed to be an especially important issue for parents, given the central role they play in the socialization and development of their children. Existing evidence indicated that high self-esteem individuals are more capable and competent (Burns, 1979). They are more aware of and sensitive to the cues of others (Walster \& Walster, 1978), which enables them to be more responsive and sensitive to those with whom they interact. In a family, parents with higher self-esteem would be expected to present more positive interactions with their children and perform more effectively their parental role. Small's findings indicate that there is a relationship between a parent's sense of self-worth and the behaviors he or she employs when interacting with preadolescent and adolescent offspring (Small, 1988). He found a significant relationship between parental self-esteem and a particular parent-child interaction variable, and this relationship was true only for mothers. At least, the parenting role appears to be more central to the mother's sense of self than to the father's. He found a strong positive relationship between parental self-esteem and parent-child communication. This relationship held for both mothers and fathers. Parents with higher 
self-esteem were more likely to have friendly discussions with their children (Small, 1988).

According to some researchers who postulated the "intergenerational transmission", the individuals whose parents are not available and responsive to their needs have more chances to experience later difficulties to develop stable couple relationships and in serving as a secure base for their own children (Bretherton \& Munholland, 1999). As attachment theory suggested, the working model of attachment developed from the communication between caregiver and child. Thus, communication is an important way by which attachment bonds are developed, maintained, and negotiated everyday (Bretherton, 1988; Kobak \& Duemmler, 1994). Some researches about mother-infant relationships gave support to the hypotheses that there is a link between open, sensitive communication and attachment security. Mothers of secure infants show a conversational pattern marked by responsiveness, attentiveness, and calm, soothing tone; conversely, secure infants tend to engage their mothers in direct communication (Grossmann \& Grossmann, 1984; Grossmann, Grossmann, \& Schwan, 1986). Further, Kobak and Duemmler proposed that parent-child conversations that foster understanding of differences are critical to attachment security in childhood and adolescence. When parents adopt destructive conflict behaviors in interactions with their children, they may send the implicit message that offspring's needs and feelings are not important. This message possibility evokes negative working models of self and others (Feeney, 2006). In addition, however, offspring in these families are not likely learning important social skills and may enact the maladaptive relationship behavior modeled by parents (Pettit \& Clawson, 1996). Birtchnell (1993) and Gittleman et al. (1998) found that negative correlation occurred between emotional warmth and measures of insecure attachment in all three attachment measures. Perris and Andersson (2000) found a significant positive relationship between the experience of emotional warmth and indicators of secure attachment as well as a significant negative relationship between experiences of dysfunctional parenting and measures of insecure attachment. Furthermore, these relationships were consistent across three attachment measures. Schumacher et al.(2004) showed that secure adult attachment pattern in intimate relationships is associated with a parental rearing behavior that has been perceived as positive, while on the other hand insecure attachment patterns are rather associated with more negative experiences of parental rearing. Li (2006) tested the relationship between attachment to mother and parental rearing in a sample of 246 mothers with children in 
the fifth grade. He found that attachment avoidance was significantly related to three rearing styles: warmth and understanding, rejection and deny, and over-involvement, whereas attachment anxiety was positively related to punishment, rejection and deny, and over-protection. Evermore, the scores of secure and fearful mothers are higher on rejection and denial, over-involvement than dismissing and preoccupied mothers.

Despite evidence that parental insecurity is linked to ineffective parent-child communication (including conflict-centered communication) and to offspring's own insecurity, the underlying mechanisms are still not clear. Although parental care is deemed to be influential in children's psychological development, many clinicians and researchers have paid much more attention to maternal care than paternal care. Matsuoka et al. (2006) give evidences that paternal care predicts secure adult attachment in both men and women, but that paternal protection has little predictive power. In contrast, maternal care predicts secure adult attachment only in women, while low maternal protection predicts secure adult attachment only in men. In the present study, we want to test the relationship between parental feelings about him- or herself, positive and negative parental rearing behaviors and adolescent adult attachment dimensions.

\section{Research Hypotheses}

Hypothesis 1: maternal and paternal self-esteem will be negatively correlated with adolescent anxiety and avoidance to parents.

Hypothesis 2: dysfunctional parental rearing behaviors will be positively correlated with adolescent anxiety and avoidance to parents.

Hypothesis 3: positive parental rearing behaviors will be negatively correlated with adolescent anxiety and avoidance to parents.

\section{Method}

Participants - A written advertisement for participants in a study about parental self-esteem, parental rearing behaviors, and adolescent adult attachment was sent to high school teachers in three areas of China (Beijing; Gansu and Shandong province). About 500 students were recruited. Parents also took part in this research completing The Rosenberg Self-Esteem Scale while students completed the EMBU and the ECR 
scales. Only those who submitted all the parents-child dyad questionnaires were taken into account. Hence, the sample was composed of 448 adolescent participants including 209 males adolescents (mean age and SD of 17.9 and 1.08), 174 females adolescents (mean age and SD of 17.4 and 0.80), 65 with missing gender information; 448 parents participants including 360 fathers (mean age and SD of 44.8 and 4.5), 360 mothers (mean age and SD of 43.5 and 3.3), 88 fathers and 88 mothers with missing gender information. The background characteristics of the participants are presented in Table 1.

Table 1. Participants and Background Characteristics

\begin{tabular}{|c|c|c|}
\hline & $n$ & (\%) \\
\hline \multicolumn{3}{|l|}{ Gender } \\
\hline Boys & 209 & $(46.7 \%)$ \\
\hline Girls & 174 & $(38.8 \%)$ \\
\hline Missing & 65 & $(14.5 \%)$ \\
\hline \multicolumn{3}{|l|}{ Have siblings } \\
\hline Yes & 156 & $(34.8 \%)$ \\
\hline No & 249 & $(55.6 \%)$ \\
\hline Missing & 43 & $(9.6 \%)$ \\
\hline \multicolumn{3}{|l|}{ Mothers' Education } \\
\hline College or above & 51 & $(11.4 \%)$ \\
\hline Middle school & 316 & $(70.5 \%)$ \\
\hline Primary school or below & 38 & $(8.5 \%)$ \\
\hline Missing & 43 & $(9.6 \%)$ \\
\hline \multicolumn{3}{|l|}{ Fathers' Education } \\
\hline College or above & 92 & $(20.6 \%)$ \\
\hline Middle school & 297 & $(66.3 \%)$ \\
\hline Primary school or below & 17 & $(3.8 \%)$ \\
\hline Missing & 42 & $(9.3 \%)$ \\
\hline Total & 448 & \\
\hline
\end{tabular}

\section{Measures}

The Self-Esteem (SES) - The Rosenberg Self-Esteem Scale (SES) is a widely used 10-item self-report measure (Rosenberg, 1965) that provides a reliable index of overall self-esteem (Chubb, Fertman, \& Ross, 1997; Paterson, Pryor, \& Field, 1995). Participants rate 10 self-statements such as "I feel that I have a number of good qualities" or "All in all, I am inclined to feel that I am a failure" from strongly agree (1), agree (2), disagree (3), or strongly disagree (4). After reverse coding positively worded items, a total self-esteem score is calculated by summing all responses, with higher scores indicating higher levels of self-esteem. The Chinese version was adopted from Handbook of Mental Health Assessment Scales. The internal consistency alpha in the current sample was 0.654 and 0.686 for father and mother respectively. 
The EMBU - EMBU (a Swedish acronym for "own memories of parental rearing" (Perris et al., 1980) assesses an individual's memories of perceived parental rearing. It is comprised of 14 priori categories obtained by extensive search of the clinical and empirical literatures. The 81 questions were scored on four-point Likert scales (1 No, never; 2 Yes, but seldom; 3 Yes, often; 4 Yes, most of the time), separately for mother and father. Four factors were derived from factor analysis: guilt engendering; emotional warmth and encouragement versus love deprivation and rejection; favoring the subject over siblings; overprotection. The Chinese version was created by Yue Dongmei. The revised inventory identified 6 factors (emotional warmth, punishment, overinvolvement, favoring the subject, rejection and overprotection) from 58 items of father's parental rearing behaviors and 5 factors (emotional warmth, overinvolvement and overprotection, rejection, punishment and favoring the subject) from 57 items of mother's rearing behaviors. The Chinese version of EMBU could discriminate between healthy subjects and patients suffering from neuroses. This version has acceptable internal consistency and validity (Yue, 1993). The internal consistency alpha in the current study was 0.88 .

The Experiences in Close Relationships Scale (ECR) - This scale (Brennan et al., 1998) was derived from 323 items by self-report attachment measures which were administered to 1,086 participants. Through factor analysis, two factors were identified-anxiety (e.g., "I worry about being abandoned") and avoidance (e.g., "I prefer not to show a partner how I feel deep down") — each of which contained 18 items. The 36 items are rated on a 7-point Likert-type scale $(1=$ Disagree Strongly to $7=$ Agree Strongly). Each item was highly correlated with its total factor score. However, scores on the two scales were not correlated. The two scales indicated that the measure has strong internal consistency and construct validity. The Chinese version of the ECR was adapted by Li and Kato and applied to 307 Chinese college students. The resulting factor analysis confirmed the two factors - anxiety and avoidance. This version also had acceptable internal consistency and construct validity (Li, 2006). A modification to this measure was made for the present study. Instead of reporting attachment to "partner," subjects were asked to report separately attachment toward the mother and father. The internal consistency alpha in the current sample was 0.75 and 0.77 , respectively. 


\section{Procedure}

After receiving consent from the local school teachers and the participants, researchers sent questionnaires to each teacher and asked them to distribute the questionnaires to the students. These questionnaires were completed anonymously and then returned. After completing the questionnaires, each participant was compensated with a gift worthy of 5 Yuan (US\$ 0.64).

\section{Statistical analysis}

The data were analyzed by using the Statistical Package for Social Science (SPSS 10.0). The two dimensions of the ECR, each factor of the EMBU, SES score of fathers and mothers were calculated. The relationships between fathers SES, mothers SES, parental rearing and the adult attachment scores was calculated as Pearson's correlation. Further relationships between SES, EMBU and ECR were investigated using multiple regression analysis. Calculations were made using the scores of EMBU and ECR as dependent variables, and the SES of fathers and SES of mothers as independent variables.

\section{Results}

Partial correlation among SES of fathers and mothers, parental rearing, and attachment to parents is showed in Table 2. The results showed that fathers' SES scores were positively associated with the scores of adolescent avoidance to father $(r=0.15$, $\mathrm{p}<.01$ ), while mothers' SES scores were positively associated with not only the scores of avoidance to father $(r=0.18, \mathrm{p}<.01)$ but also the scores of avoidance to mother $(r=$ $0.18, \mathrm{p}<.01)$. The data about the relationship of parental rearing and attachment to parents showed that, 1) the scores of avoidance to mother were negatively associated with the scores of father's care and emotional warmth $(r=-0.37, \mathrm{p}<.01)$, mother's care and emotional warmth $(r=-0.36, \mathrm{p}<.01)$, and positively associated with paternal punitiveness $(r=0.21, \mathrm{p}<.01)$, paternal overinvolvement $(r=0.14, \mathrm{p}<.05)$, paternal denying and rejecting $(r=0.28, \mathrm{p}<.01)$ and maternal overinvolvement and overprotection $(r=0.19, \mathrm{p}<.01)$, maternal denying and rejecting $(r=0.23, \mathrm{p}<.01)$, maternal punitiveness $(r=0.24, \mathrm{p}<.01) ; 2)$ the scores of anxiety to mother were positively associated with paternal punitiveness $(r=0.25, \mathrm{p}<.01)$, paternal overinvolvement $(r=0.22, \mathrm{p}<.01)$, paternal denying and rejecting $(r=0.25, \mathrm{p}<.01)$, parental overprotection $(r=0.15, \mathrm{p}<.01)$ and maternal overinvolvement and 
overprotection $(r=0.19, \mathrm{p}<.01)$, maternal denying and rejecting $(r=0.26, \mathrm{p}<.01)$, maternal punitiveness $(r=0.25, \mathrm{p}<.01) ; 3)$ the scores of avoidance to father were negatively associated with the scores of father's care and emotional warmth $(r=-0.35$, $\mathrm{p}<.01)$, mother's care and emotional warmth $(r=-0.33, \mathrm{p}<.01)$, and positively associated with paternal punitiveness $(r=0.15, \mathrm{p}<.05)$, paternal overinvolvement $(r=$ $0.14, \mathrm{p}<.05)$, paternal denying and rejecting $(r=0.22, \mathrm{p}<.01)$, parental overprotection $(r$ $=0.16, \mathrm{p}<.01)$ and maternal overinvolvement and overprotection $(r=0.20, \mathrm{p}<.01)$, maternal denying and rejecting $(r=0.22, \mathrm{p}<.01)$, maternal punitiveness $(r=0.23$, $\mathrm{p}<.01)$; 4) the scores of anxiety to father were positively associated with paternal punitiveness $(r=0.31, \mathrm{p}<.01)$, paternal overinvolvement $(r=0.25, \mathrm{p}<.01)$, paternal denying and rejecting $(r=0.27, \mathrm{p}<.01)$, parental overprotection $(r=0.19, \mathrm{p}<.01)$ and maternal overinvolvement and overprotection $(r=0.21, \mathrm{p}<.01)$, maternal denying and rejecting ( $r=0.31, \mathrm{p}<.01)$, maternal punitiveness $(r=0.28, \mathrm{p}<.01)$, maternal favoring the subject $(r=0.20, \mathrm{p}<.01)$.

Table 2. Partial Correlation between SES of fathers and mothers, parental rearing, and attachment to parents $(\mathrm{N}=448)$.

\begin{tabular}{|c|c|c|c|c|}
\hline & $\begin{array}{c}\text { Avoidance } \\
\text {-Mother }\end{array}$ & $\begin{array}{l}\text { Anxiety } \\
\text {-Mother }\end{array}$ & $\begin{array}{c}\text { Avoidance } \\
\text {-Father }\end{array}$ & $\begin{array}{l}\text { Anxiety } \\
\text {-Father }\end{array}$ \\
\hline \multicolumn{5}{|l|}{ SES of parents } \\
\hline SES of father & 0.03 & 0.10 & $0.15^{* *}$ & 0.06 \\
\hline SES of mother & $0.18 * *$ & 0.07 & $0.18 * *$ & 0.05 \\
\hline \multicolumn{5}{|l|}{ EMBU scales-Father } \\
\hline care and emotional warmth & $-0.37 * *$ & -0.00 & $-0.35^{* *}$ & -0.01 \\
\hline punitive & $0.21 * *$ & $0.25^{* *}$ & $0.15^{*}$ & $0.31 * *$ \\
\hline overinvolved & $0.14 *$ & $0.22 * *$ & $0.14 * *$ & $0.25^{* *}$ \\
\hline favoring the subject & -0.05 & 0.13 & -0.09 & $0.20 * *$ \\
\hline denying and rejecting & $0.28 * *$ & $0.25^{* *}$ & $0.22^{* *}$ & $0.27 * *$ \\
\hline overprotective & 0.10 & $0.15^{* *}$ & $0.16 * *$ & $0.19 * *$ \\
\hline \multicolumn{5}{|l|}{ EMBU scales-Mother } \\
\hline care and emotional warmth & $-0.36^{* *}$ & -0.05 & $-0.33 * *$ & -0.05 \\
\hline overinvloved and overprotective & $0.19 * *$ & $0.19 * *$ & $0.20 * *$ & $0.21 * *$ \\
\hline denying and rejecting & $0.23 * *$ & $0.26 * *$ & $0.22 * *$ & $0.31 * *$ \\
\hline punitive & $0.24 * *$ & $0.25 * *$ & $0.23 * *$ & $0.28 * *$ \\
\hline favoring the subject & -0.05 & 0.12 & -0.08 & $0.20 * *$ \\
\hline \multicolumn{5}{|l|}{ Attachment to parents } \\
\hline Avoidance-Mother & 1 & -0.05 & $0.51 * *$ & -0.01 \\
\hline Anxiety-Mother & -0.05 & 1 & 0.03 & $0.70 * *$ \\
\hline Avoidance-Father & $0.51 * *$ & 0.03 & 1 & -0.06 \\
\hline Anxiety-Father & -0.01 & $0.70 * *$ & -0.06 & 1 \\
\hline
\end{tabular}


To examine whether or not parental self-esteem and parental rearing accounted for a significant proportion of the variance in avoidant and anxiety scores to each parent, a series of stepwise regression analyses was carried out. The main results of these regressions are presented in Table 3. As shown, neither mother's SES nor father's SES can predict the adolescent attachment to parents. However, there are significant parental rearing behaviors which can predict adolescent attachment to parents. As showed in Table 3, parental denying and rejecting, parental care and emotional warmth appeared to be a significant predictor of avoidance of mother $(\beta=0.257, \quad p<.01 ; \beta=-0.235$, $\mathrm{p}<.01$ ), while they had difference direction, accounted for a modest but significant proportion of the variance. Parental denying and rejecting also can predict anxiety to father $(\beta=0.378, p<.01)$, and parental care and emotional warmth seem to predict avoidance to father in another direction $(\beta=-0.223, \mathrm{p}<.01)$. Comparing to the father's rearing behaviors, maternal punitiveness can predict anxiety to mother $(\beta=0.216$, $\mathrm{p}<.01$ ), maternal overinvolvement and overprotection can predict avoidant to father as well $(\beta=0.182, \mathrm{p}<.05)$.

Table 3. Main results of stepwise regression analyses with SES of fathers and mothers, and EMBU scales being predictors and attachment to father and mother scores being the dependent variable

\begin{tabular}{llccc}
\hline Dependent Variables & \multicolumn{1}{c}{ Predictors } & $\beta$ & $\mathrm{p}$ & $\mathrm{R}^{2}$ change \\
\hline & \multicolumn{2}{c}{ EMBU scales-Father and attachment to parents } & & \\
Avoidance-Mother & denying and rejecting & 0.257 & $<0.01$ & 0.097 \\
Avoidance-Mother & care and emotional warmth & -0.235 & $<0.01$ & 0.052 \\
Anxiety-Father & denying and rejecting & 0.378 & $<0.01$ & 0.143 \\
Avoidance-Father & care and emotional warmth & -0.223 & $<0.01$ & 0.047 \\
& EMBU scales-Mother and attachment to parents & & \\
Anxiety-Mother & punitive & 0.216 & $<0.01$ & 0.047 \\
Avoidance-Father & overinvolved and overprotective & 0.182 & $<0.05$ & 0.033 \\
\hline
\end{tabular}




\section{Discussion}

\section{Parents Self-esteem and adolescent attachment to parents}

Some evidence showed that high self-esteem persons are more capable and competent (Burns, 1979). Small (1988) found a significant relationship between parental self-esteem and a particular parent-child interaction variable when interacting with preadolescent and adolescent offspring. He postulated that the parenting role appears to be more central to the mother's sense of self than the father's. Although our data showed that fathers' SES scores were positively associated with the scores of adolescent avoidance to father, while mothers' SES scores were positively associated with not only the scores of avoidance to father but also the scores of avoidance to mother, the father's SES and mother's SES can predict neither dimension of attachment to parents. That might mean that the parents' SES has no clear relationship with adolescent attachment to parents. So, our data do not confirm our hypotheses. This might have some reasons. First, we adopted the global self-esteem assessment to test the relationship. Rosenberg et al. (1995) postulated that global self-esteem appears to be heavily affective in nature and tends to be associated with overall psychological wellbeing. In contrast, specific self-esteem is more judgmental and evaluative, and it appears to have a more cognitive component and tends to be more strongly associated with behavior or behavioral outcomes. So, in the present study, the global parents' selfesteem showed no effect on the adolescent attachment to parents. Second, the relationship of parents' self-esteem and children attachment was not directly related, there might be some moderator or mediator between these variables, which should be further investigated.

\section{Parental rearing behavior and adolescent attachment to parents}

The present study showed that the parents rearing behavior has significant relationship with attachment to parents. The positive parental rearing behaviors were negatively associated with avoidance to mother and avoidance to father. And that the dysfunctional parental rearing behaviors were positively associated with avoidance to mother and father, anxiety to father and mother. With stepwise regression, we found that paternal denying and rejecting can predict avoidance to mother and anxiety to 
father, while parental care and emotional warmth can predict avoidance to mother and avoidance to father respectively. Concerning mothers' rearing behaviors, we found that maternal punitiveness can predict adolescent anxiety to mother, while maternal overinvolvement and over-protection can predict adolescent avoidance to father. These results were similar to other western and Chinese researches (Perris \& Andersson, 2000; Schumacher et al.,2004; Li, 2006). The results of the present study indicated that parental positive rearing behaviors were negatively associated with avoidance to both parents. That might mean that adolescents felt safe and comfortable with maternal and paternal care and emotional warmth, giving support to them, expressing less avoidance behavior when they stayed with their parents. However, parental dysfunctional rearing behaviors were positively associated with avoidance and anxiety to mother and father. Paternal denying and rejecting was associated with avoidance to mother and anxiety to father. Bartholomew (1990) named two dimensions of attachment: the "model of self" and the "model of others." A negative model of self is associated with anxiety about abandonment and a negative model of others leads to avoidant behavior. Paternal denying and rejecting affect the relationship between adolescents and others. They might show avoidant behavior when they communicated with parents, especially for mother. Furthermore, paternal denying and rejecting influence the adolescent model of self negatively. They felt anxiety when stayed with the father. Similarly, maternal punitiveness also influence the adolescent model of self negatively, these rearing behavior made them feel anxiety. Maternal overinvolved and overprotective behavior seems to have positive effect which can account for a significant proportion of the variance in the scores of adolescent avoidance to father. These finding are consistent with the notion that family environment factors such as parental rearing contribute to the severity of anxiety and avoidance to parents in adolescents.

In sum, parental global self-esteem seems to have no effect on adolescent attachment to parents. Parental positive rearing behaviors were significantly associated with avoidance to parents. The dysfunctional rearing behaviors, such as paternal denying and rejecting, maternal punitiveness, maternal overinvolvement and overprotection, can predict the adolescent avoidance and anxiety to parents. 
The research was a cross-sectional study and further work examining the relationship between family factors and adolescent attachment to parents should benefit from the use of multiple time-points and multiple measures, for example, using longitudinal design. Further studies should adopt not only the global self-esteem of parents but also their specific self-esteem, such as self-esteem about rearing behaviors. Moreover, in the present study we have not discussed mediator or moderator factors between family and attachment to parents. Further investigation could test if these variables might give more light to understand these topics.

\section{References}

Bartholomew, K. (1990). Avoidance of intimacy: An attachment perspective. Journal of Social and Personal Relationships, 7, 147-178.

Birtchnell J. (1993). Does recollection of exposure to poor maternal care in childhood affect later ability to relate? British Journal of Psychiatry. 162: 335-344.

Bowlby, J. (1973). Attachment and loss. Vo1. 1. Pimli, Co.

Bowlby, J. (1988). A Secure Base. New York: Basic Book

Brennan, K. A., Clark, C. L., \& Shaver, P. R. (1998). Self-report measurement of adult attachment: An integrative overview. In: Simpson J A \& Rholes W S eds. Attachment theory and close relationships. New York: The Guilford Press

Bretherton, I., \& Munholland, K. A. (1999). Internal working models in attachment relationships: A construct revisited. In J. Cassidy \& P. R. Shaver (Eds.), The handbook of attachment: Theory, research, and clinical applications: 89-111. New York: Guilford.

Feeney, J.A. (2006). Parental attachment and conflict behavior: Implications for offspring's attachment, loneliness, and relationship satisfaction. Personal Relationships, 13, 19-36

Gittleman, M.G., Klein, M.H., Smider, N.A. \& Essex, M.J. (1998).Recollections of parental behaviour, adult attachment and mental health: mediating and moderating effects. Psychological Medicine. 28, 1443-1455. 
Greenberg, M. T. (1999). Attachment and psychopathology in childhood. In J. Cassidy \& P. R. Shaver (Eds), Handbook of attachment: Theory, research, and clinical (pp. 469 - 496). New York: Guilford Press.

Li, T.G. \& Kato, K. (2006). Measuring Adult Attachment: Chinese Adaptation of the ECR Scale. Acta Psychologica Sinica, 38(3), 399-406.

Li, T.G. (2006). Patterns of attachment in adulthood and rearing style. Chinese Journal of Behavior Medical Science, Vol. 15(2):149-151

Matsuoka, N., Uji, M., Hiramura, H., Chen, Z., Shikai, N., Kishida, Y., et al. (2006). Adolescents' attachment style and early experiences: A gender difference. Health Archives of Women's Mental Health, 9(1), 23-29.

Morris R, Carmi S, Carrie S \& Florence R. (1995). Globle self-esteem and specific selfesteem: different concepts, different outcomes. American Sociological Review, Vol. 60(1): 141-156

Owens, T. J. (1993). Accentuate the Positive and the Negative: Rethinking the Use of Self-Esteem, Self-Deprecation and Self-Confidence. Social Psychology Quarterly, $56,288-299$.

Perris, C. \& Andersson, P. (2000). Experiences of Parental Rearing and Patterns of Attachment in Adulthood. Clinical Psychology and Psychotherapy, 7, 279-288.

Perris, C., Jacobsson, L., Lindström, H., von Knorring, L. \& Perris, H. (1980). Development of a new inventory for assessing memories of parental rearing behaviour. Acta Psychiatrica Scandinavica, 61, 265-274.

Schumacher, J., Stöbel-Richter, Y., Strauss, B., \& Brähler, E. (2004). Perceived parental rearing behaviour and adult attachment patterns in intimate relationships. Psychotherapie, Psychosomatik, Medizinische Psychologie, 54 (3-4), 148-154.

Small, S.A. (1988). Parental Self-Esteem and Its Relationship to Childrearing Practices, Parent-Adolescent Interaction, and Adolescent Behavior. Journal of Marriage and the Family, 50 (4), 1063-1072.

Wang, X.D. (1993). Handbook of mental health assessment Scales. Chinese Mental Health Journal (Supplement). 83-84. 